\title{
BAMBOO AND PINEAPPLE LEAF FIBER REINFORCED NEEM SHELL LIQUID COMPOSITES
}

\author{
T. SRINAG ${ }^{1, *}$, V. NAGA PRASAD NAIDU ${ }^{2} \&$ K. HEMACHANDRA REDDY ${ }^{3}$ \\ ${ }^{I}$ Research scholar, Jawaharlal Nehru Technological University Anantapur, Andhra Pradesh, India \\ ${ }^{2}$ Professor, Department of Mechanical Engineering, JNTUA College of Engineering Kalikiri, Andhra Pradesh, India \\ ${ }^{3}$ Professor, Department of Mechanical Engineering, Jawaharlal Nehru Technological University Anantapur,
}

Andhra Pradesh, India

\begin{abstract}
With the view of exploring the potential use of natural resources, an attempt is made to fabricate novel green composites. Novel green composites are fabricated by reinforcing Bamboo and Pineapple fibers in bio degradable Neem shell liquid (resin) by hand lay-up technique. Tensile, bending and impact tests were performed at various weight percentages of fiber. The results revealed that tensile strength, tensile modulus, bending strength, bending modulus and impact strength values will increase initially with fiber content and later decrease. The optimum value of fiber content is 20 wt.\%. Bamboo fiber exhibited better properties in tensile and flexural tests while Pineapple fiber showed better results during impact loading. The NSL composite exhibited $236 \%$ improvement in tensile strength when reinforced with Bamboo fibers and $90 \%$ improvement when reinforced with PALF at 20 wt.\%. The NSL composite exhibited $275 \%$ improvement in flexural strength when reinforced with Bamboo fibers and $236 \%$ improvement when reinforced by PALF at 20 wt.\%. The NSL composite exhibited $34 \%$ improvement in Impact Strength when reinforced with Bamboo fibers and $88.7 \%$ improvement when reinforced by PALF at 20 wt.\%.
\end{abstract}

KEYWORDS: Green Composites, Bamboo Fiber, Pineapple FIBER \& Neem Shell Liquid

Received: May 25, 2020; Accepted: Jun 15, 2020; Published: Jun 30, 2020; Paper Id.: IJMPERDJUN2020175

\section{INTRODUCTION}

Nature is always generous with mankind by providing different types of resources in abundance for his living and existence. With the drastic increase in population and to meet the needs the mankind is using these resources extensively. Some of these resources are renewable and some are non-renewable. The most important non renewable resources are metals and fossil fuels. Metals are used since 1200 BC, new metals and alloys are developed and used for various applications. The advantages of metals are capability to withstand high temperature, fire resistance, high transverse strength and stiffness, wear resistant, good hardness, no moisture absorption, good electrical and thermal conductivities. However their disadvantages are higher cost, complex production methods and corrosion. To overcome these difficulties metals are replaced by polymers in certain applications like aerospace, automobile, packing, sports and goods etc. [1]. Petroleum and natural gas are used in the manufacturing of plastics, they may last only for next 40- 60 years if they are consumed at this rate. As polymers are the byproducts of petroleum, they are non-renewable, non-recyclable, non-biodegradable, consume high energy during their manufacture and also cause health risk when inhaled [2]. Hence researchers have put efforts in identifying substitute materials which can replace polymers and monolithic materials for the sustainable development. Natural fibers are easily available, cheap, renewable, biodegradable, poses good mechanical strength, low density and good acoustic properties. In addition, 
fibers require low processing energy, impose fewer health hazards, have a positive impact on their biodegradability and thus help reduce carbon emissions [3]. Thus the thought of using naturally available renewable materials in partial replacement to petroleum-based plastic material has given the scope for a large area of research. These natural materials are plant, animal and mineral based. Natural fibers like Agave, Areca, Bamboo, Banana, Basalt, Bagasse, Corn, Coir, Cotton, Flax, Hemp, Jute, Kenaf, Palm, Pineapple leaf, Ramie, Rice husk, Sisal, Ukam and Wood flour are available in many nations in large quantities and are considered as continuous source of renewable material [4]. They can be used as reinforcement material in developing a new variety of materials called green or bio-degradable composites. Green composites are composites, where the matrix or the reinforcement or both are made of biodegradable materials.

As per the European Guideline 2000/53/EG, $85 \%$ of the vehicle weight had to be recyclable. However some of the automobile manufacturers around the globe are aiming at $95 \%$ recyclability. The establishment of such a standard encouraged the usage of bio degradable and recyclable materials leading to cost savings, weight reduction, improvement in fuel efficiency and environmental protection. Many of the well-known automotive manufacturers are using bio-fiber composites for different interior and exterior parts [5]. There is no much literature available on NSL hence it is considered as a novel material for preparation of green composites.

\section{MATERIALS AND METHODS}

Pineapple Leaf Fibers, Bamboo fibers, NSL resin and Hardener are procured from Vruksha composites and Services, Morriespet, Tenali, Andhra Pradesh, India.

\subsection{Pineapple Leaf Fiber (PALF)}

Pineapple plant belongs to Bromeliaceae family. Pineapple leaf (PAL), is roughly 3' long and 2" to 3" wide. Leaves yield only 2 to $3 \%$ fiber. PALF has cellulose (81.27\%), hemicelluloses (12.31\%) and lignin (3.46\%). Fiber extraction from PAL is done by mechanical methods as well as other methods like retting. PALF appears whitish in colour. It is smooth and glossy like silk. It has got high specific strength, stiffness and torsional rigidity.

PALF can be used as sound absorber, thermal insulator etc. Due to lack of knowledge PALF is not utilized properly. The hydrophilic nature of PALF is because of its high cellulose content. It is softer than other natural fibers. PALF could be a better substitute for synthetic fibres, because it is biodegradable, cheap and renewable in nature. The physical properties of PALF depend on method of extraction, age of the plant, plant cultivation conditions etc. The strength properties of any fiber reinforced composite depend on amount of bonding between fiber and matrix, wt. \% of fiber, length to diameter ratio, fiber direction and efficiency to transfer stress at the interface [6]. Table1 represents the physical and mechanical properties of PALF.

Table 1: Properties PALF [6]

\begin{tabular}{|c|c|c|c|c|c|}
\hline Fiber & $\begin{array}{c}\text { Density } \\
\left(\mathbf{g} / \mathbf{c m}^{\mathbf{3}}\right)\end{array}$ & $\begin{array}{c}\text { Young's Modulus } \\
(\mathbf{G P a})\end{array}$ & $\begin{array}{c}\text { Elongation at Break } \\
(\mathbf{\%})\end{array}$ & $\begin{array}{c}\text { Tensile Strength } \\
(\mathbf{M p a})\end{array}$ & $\begin{array}{c}\text { Specific Modulus } \\
(\mathbf{G P a})\end{array}$ \\
\hline Pineapple Leaf & 1.4 & $34.5-82.51$ & $1.6-3$ & $413-1627$ & $22.7-54.3$ \\
\hline
\end{tabular}

\subsection{Bamboo Fibers}

Bamboo fibers exhibit good mechanical properties like low elongation at break and high tensile modulus. Due to low density of Bamboo its specific properties like specific strength and specific stiffness are as good as those of Glass fibers. The major constituents in Bamboo fiber are Cellulose, Hemi-cellulose and Lignin. The minor constituents of Bamboo fiber 
are resins, tannins, waxes and inorganic salts. There are many methods for extracting Bamboo fiber from Bamboo such as mechanical processing, chemical processing and biological degumming etc. The fibres are antifungal, antibacterial, bacteriostatic, hypoallergenic, hydroscopic, natural deodorizer and resistant against ultraviolet light [7]. Table 2 represents mechanical and physical properties of Bamboo fibers.

Table 2: Properties of Bamboo Fibers [7]

\begin{tabular}{|c|c|c|c|c|}
\hline Fiber & $\begin{array}{c}\text { Density } \\
\left(\mathbf{g} / \mathbf{c m}^{\mathbf{3}}\right)\end{array}$ & $\begin{array}{c}\text { Young's Modulus } \\
(\mathbf{G P a})\end{array}$ & $\begin{array}{c}\text { Elongation at Break } \\
(\mathbf{\%})\end{array}$ & $\begin{array}{c}\text { Tensile Strength } \\
(\mathbf{M P a})\end{array}$ \\
\hline Bamboo fiber & $0.8-1.1$ & $48-89$ & $1.9-3.2$ & $391-1000$ \\
\hline
\end{tabular}

\subsection{Neem Shell Liquid Resin}

It is a natural and bio degradable resin. When the bark of the Neem tree is removed, special ports or cavities present behind the bark secrete a liquid. This liquid is collected, processed and treated with few chemicals to produce NSL resin. It is eco friendly resin and does not cause any environment pollution. Properties of NSL are shown in table 3.

Table 3: Properties of NSL Resin

\begin{tabular}{|c|c|c|c|c|c|}
\hline \multicolumn{1}{|c|}{ Resin } & $\begin{array}{c}\text { Tensile } \\
\text { Strength } \\
\left(\mathbf{N} / \mathbf{m m}^{2}\right)\end{array}$ & $\begin{array}{c}\text { Young's } \\
\text { Modulus } \\
\left(\mathbf{N} / \mathbf{m m}^{\mathbf{2}}\right)\end{array}$ & $\begin{array}{c}\text { Flexural } \\
\text { Strength } \\
\left(\mathbf{N} / \mathbf{m m}^{\mathbf{2}}\right)\end{array}$ & $\begin{array}{c}\text { Flexural } \\
\text { Modulus } \\
\left(\mathbf{N} / \mathbf{m m}^{\mathbf{2}}\right)\end{array}$ & $\begin{array}{c}\text { Impact } \\
\text { Strength } \\
(\mathbf{J})\end{array}$ \\
\hline $\begin{array}{l}\text { Neem Shell Liquid } \\
\text { Resin }\end{array}$ & $25-26$ & $1185-1365$ & 53 & 2178 & $0.52-0.54$ \\
\hline
\end{tabular}

\subsection{Aradur Hardener}

Hardener or Binder is a material which is added to the resin so that the resin gets hard and holds its shape. It increases the bonding between atoms so that the resin gets hardened after mixing with it. Aradur is a Polyamide Imidazoline which is used with epoxy resin for solvent free or heavy filled mastic epoxy mortars. It has high degree of adhesion, flexibility and corrosive resistance.

\section{PREPARATION OF COMPOSITE SPECIMENS}

The specimens are made by using Hand-layup method. Separate moulds are made for preparing specimens for tensile, flexural and impact tests. Each mould is designed such that six specimens of given wt. \% can be made at a time. While preparing test specimens a smooth and neat vitrified tile is taken and is placed on a perfectly flat platform. A polythene sheet is spread over the vitrified tile. The acrylic mould is place on the polythene sheet. The mould cavities are coated with a releasing agent. Neem Shell Liquid and hardener (Aradur) are taken in the ratio of 2:1. The NSL and hardener are mixed thoroughly. After ensuring that there are no air bubbles, alternate layers of resin and fibers are placed in the mould cavity. A metallic roller is rolled over the top surface of the mould to ensure that any excess resin is removed. The mould is covered by another polythene sheet. Weight is placed on the mould. After forty eight hours of curing the specimens are taken out from the mould, inspected and cleaned. The specimens are soft and flexible hence they are stored in vacuum at room temperature for forty eight hours to become hard and stiff.

\section{TESTING EQUIPMENT AND SPECIMEN STANDARDS}

TENSOMETER and IMPACT TESTER are used for mechanical testing of the composites specimens. The specimen standards are discussed below. 


\subsection{Tensile Test}

It is conducted as per ASTM D638M-89 standard. The specimen dimensions are $160 \mathrm{~mm} \times 12.5 \mathrm{~mm} \times 3 \mathrm{~mm}$. The specimens are shown in figure 1. An electronic Tensometer, METM 2000 ER-I model of 2 Ton capacity is used for performing tensile test. Tensile strength and tensile modulus values are calculated from the observations made while conducting the test. A load cell of $200 \mathrm{~kg}$, a self aligned and quick grip chuck are used for testing the specimens.

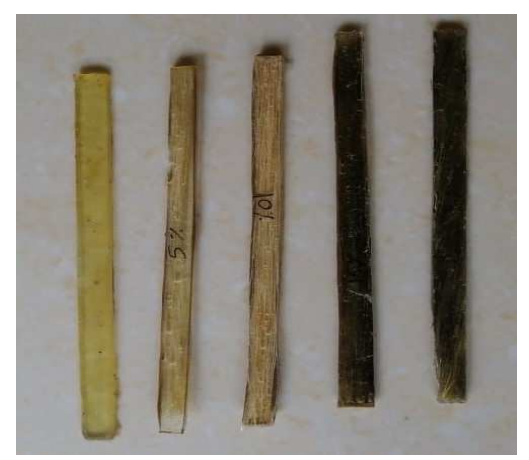

Figure 1: Tensile Test Specimens

Tensile strength indicates the maximum stress the material can take before it fails, i.e. breaking. It is an important and widely measured property of materials used for structural applications.

Tensile stress or Tensile strength $(\sigma)=$ P/A

Where

$\mathrm{P}=\operatorname{Maximum} \operatorname{load}(\mathrm{N})$,

$\mathrm{A}=$ Cross Sectional Area $\left(\mathrm{mm}^{2}\right)=$ width $(\mathrm{b}) \mathrm{x}$ thickness $(\mathrm{t})$.

The ratio of tensile stress to corresponding strain within the elastic limit is called tensile modulus.

Tensile Modulus $(\mathrm{E})=$ Tensile stress $/$ tensile strain $=[(\mathrm{P} / \mathrm{A})] /[(\delta \mathrm{L} / \mathrm{L})]$

Where, $\delta \mathrm{L}=$ Change in Length $(\mathrm{mm})$ and $\mathrm{L}=$ Original Length $(\mathrm{mm})$.

\subsection{Flexural Test}

It is performed according to ASTM D79M-86 standard. The specimen dimensions are $100 \mathrm{~mm} \times 25 \mathrm{~mm} \times 3 \mathrm{~mm}$ as shown in figure 2. A 2 Ton electronic Tensometer is used for conducting three-point bending test. The test results are noted and flexural strength, flexural modulus values are determined.

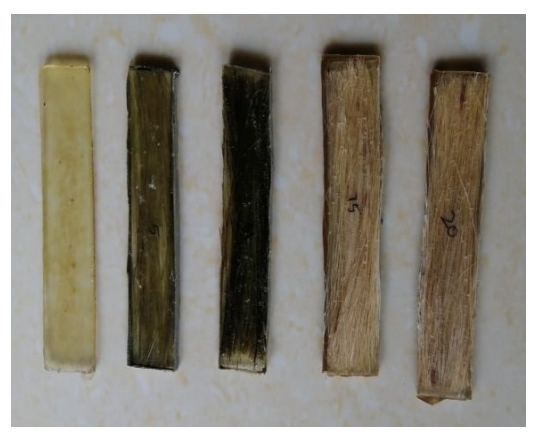

Figure 2: Flexural Test Specimens. 
Flexural strength, also known as transverse rupture strength or bending strength is an important property of materials used for structural applications. It is defined as the stress developed in the material before it yields when subjected to flexural loading. Flexural or bending modulus is ratio of stress developed to the amount of strain the material undergoes during flexural loading. It is the tendency of the material to resist bending loads.

Flexural or Bending Strength $(\sigma)=3 P L /\left(2 b^{2}\right)$

Flexural or Bending Modulus $\left(E_{b}\right)=L^{3} \mathrm{~m} /\left(4 b t^{3}\right)$

Where

$\mathrm{m}=$ Slope of load deflection curve $(\mathrm{N} / \mathrm{mm})$,

$\mathrm{b}=$ Width of specimen $(\mathrm{mm})$,

$\mathrm{t}=$ Thickness of specimen $(\mathrm{mm})$,

$\mathrm{P}=\operatorname{Maximum} \operatorname{load}(\mathrm{N})$,

$\mathrm{L}=$ Span length of the specimen (mm).

\subsection{Impact Test}

It is performed according to ASTM D256-97 standard. The dimensions of the specimen are $63.5 \mathrm{~mm} \times 10 \mathrm{~mm} \times 10 \mathrm{~mm}$ as shown in figure $3 . \mathrm{V}$ notch of $45^{\circ}$ and depth $2 \mathrm{~mm}$ is cut on the specimen. The Impact testing machine is used for testing the specimens. The maximum energy of the machine is 22J. The IZOD impact test is conducted and impact strength is determined.

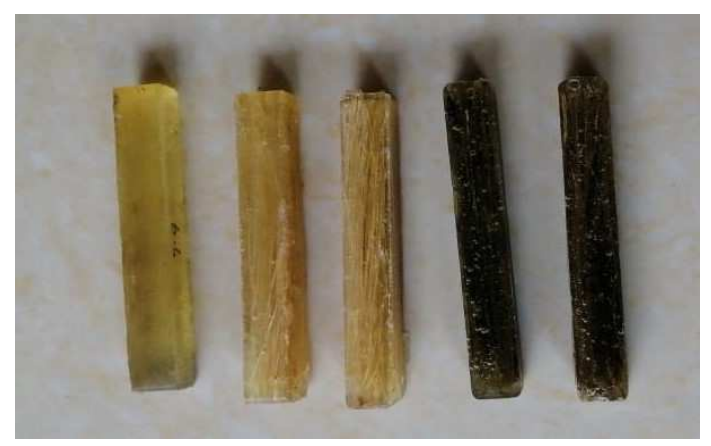

Figure 3: Impact Test Specimens before Cutting v Notch.

The capability of the material to resist a suddenly applied load or force is called impact strength. It is also stated as the energy absorbed by the material in the process of deformation under the applied impact load. Izod/ Charpy test is conducted on impact testing machine.

Impact Strength $(\mathbf{I})=\mathbf{E} / \mathbf{t}$

Where

$\mathrm{E}=$ Energy absorbed by the specimen $(\mathrm{J})$,

$\mathrm{t}=$ specimen thickness $(\mathrm{mm})$. 


\section{RESULTS AND DISCUSSIONS}

\subsection{Tensile Properties}

Variation in tensile strength with fiber wt. \% is shown in figure 4. Tensile strength of neat NSL is $26.13 \mathrm{MPa}$. Tensile strength increases with fiber wt. \%. Composites exhibited maximum tensile strength at $20 \mathrm{wt}$. $\%$ of fiber. With further increase in fiber wt. $\%$ the tensile strength decreases [8-13]. The NSL composite exhibited $236 \%$ improvement in tensile strength when reinforced with Bamboo fibers and $90 \%$ improvement when reinforced with PALF at 20 wt. $\%$ of fiber. Tensile strength of NSL- Bamboo composite is more than NSL- PALF composite. At lower fiber wt. \% there will be good interface between the fiber and matrix which leads to a strong bond between them. As wt. \% of the fiber increases the number of fibers taking the load increases, hence the tensile strength increases. But at higher fiber wt. \%, the possibility of fiber agglomeration is more. At this point the fiber matrix interface is poor and it leads to easy debonding of fibers and composite fails at lower loads.

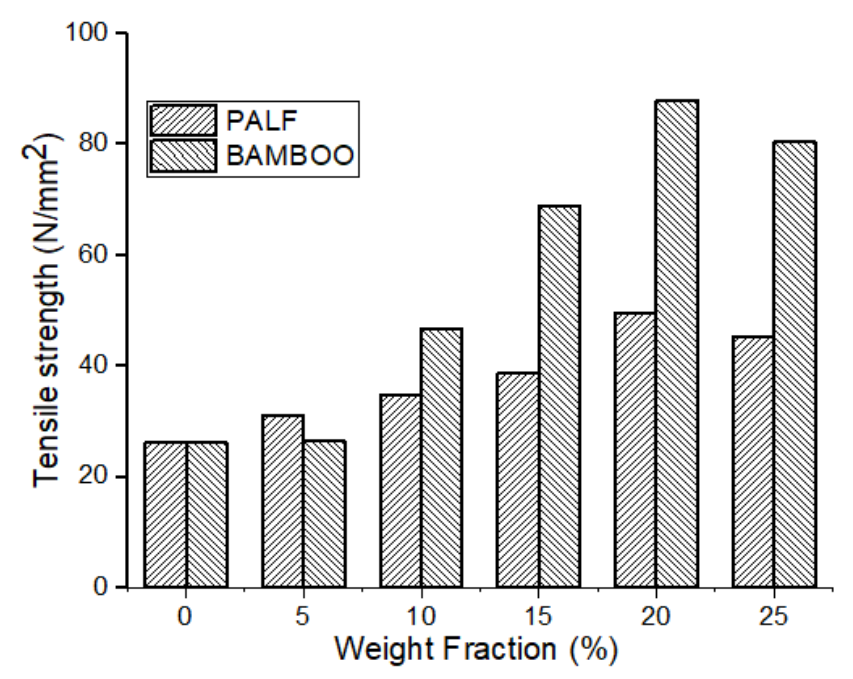

Figure 4: Weight Fraction of Fiber vs. Tensile Strength.

The purpose of reinforcing fibers in matrix is to increase the stiffness of the composite material. The increase in tensile modulus is due to increase in fiber wt. \% in softer matrix. Variation of tensile modulus with respect to fiber wt. \% is shown in figure 5. The tensile modulus of neat NSL is 1275.1 MPa. Tensile modulus of Bamboo- NSL composite increases with increase in fiber wt. \%. The Bamboo- NSL composite exhibited maximum tensile modulus at $20 \%$ fiber content. With further increase in fiber wt. \% there is decline in tensile modulus [8-13]. The NSL composite exhibits $162 \%$ improvement in tensile modulus when reinforced with Bamboo at fiber content of $20 \mathrm{wt} . \%$.

Where as when NSL is reinforced with PALF a similar trend is observed but the maximum tensile modulus is observed at a fiber content of $10 \mathrm{wt}$. \%. There is $10 \%$ increase in tensile modulus when reinforced with PALF. Tensile modulus of NSL- Bamboo composite is more than NSL- PALF composite. At higher fiber wt. \% due to agglomeration of fibers the tensile modulus decreases. 


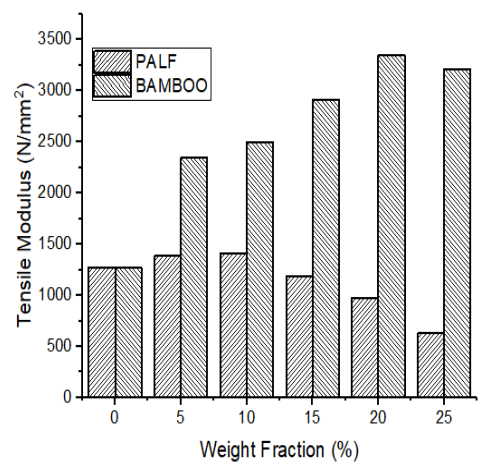

Figure 5: Weight Fraction of Fiber vs. Tensile Modulus.

\subsection{Flexural Properties}

Figure 6 shows variation in flexural strength with fiber wt. \%. The flexural strength of neat NSL is 53.28 MPa. The flexural strength of composite increases with fiber wt. \%. The composites exhibited maximum flexural strength at fiber content of 20 wt. \%. With further increase in fiber wt. \% there is decline in flexural strength [8-13]. The NSL composite exhibits $275 \%$ improvement in flexural strength when reinforced with Bamboo fibers and $236 \%$ improvement when reinforced with PALF at 20 wt. \% of fiber. Flexural strength of NSL- Bamboo composite is better than NSL- PALF composite. Increase in flexural strength with increases in fiber wt. \% can be attributed to the increase in surface area of the fiber in the matrix. The fiber which is known to have high crystalline content is therefore expected to share the applied load effectively with the crystalline fibrils in it. But at high fiber wt. \% due to agglomeration and voids the flexural strength decreases.

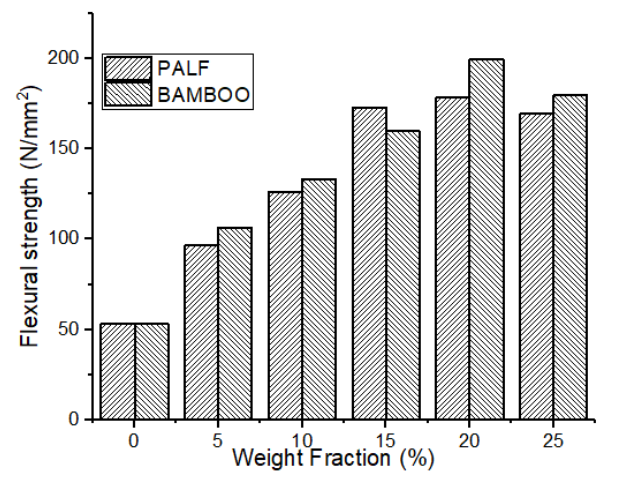

Figure 6: Weight Fraction of Fiber vs. Flexural Strength.

Figure 7 shows variation in flexural modulus with fiber wt. \%. The flexural modulus of neat NSL is 2178.64 MPa. The flexural modulus of composite increases with fiber wt. \%. The composites exhibited maximum flexural modulus at 20 wt. $\%$ of fiber. With further increase in fiber wt. \% there is decrease in flexural modulus [8-13]. The NSL composite exhibits $1085 \%$ improvement in flexural modulus when reinforced with Bamboo fibers and 316\% improvement when reinforced with PALF at fiber content of $20 \mathrm{wt}$ \%. Flexural modulus of NSL- Bamboo composite is better than NSLPALF composite. 


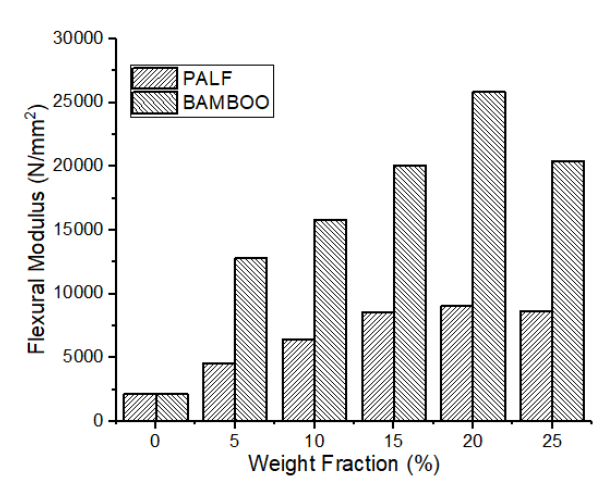

Figure 7: Weight fraction of Fiber vs. Flexural Modulus.

\subsection{Impact Properties}

Impact strength variation with fiber content is shown in figure 8. The Impact strength of neat NSL is $0.53 \mathrm{~N} / \mathrm{mm}$. The Impact strength of composite increases with fiber wt. \%. The composites exhibited maximum Impact strength at fiber content of $20 \mathrm{wt} . \%$. With further increase in fiber wt. \% there is decrease in Impact strength [8- 13]. The NSL composite exhibits 34\% improvement in Impact strength when reinforced with Bamboo fibers and 88.7\% improvement when reinforced with PALF at 20 wt. \% of fiber. Impact strength of NSL- PALF composite is better than NSL- Bamboo composite.

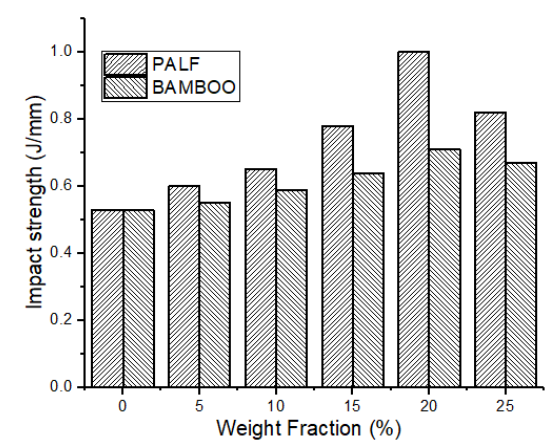

Figure 8: Weight Fraction of Fiber vs. Impact Strength.

\section{CONCLUSIONS}

- From the experimental results it is clear that tensile strength increases with fiber wt. \% (up to 20\%) and later decreases with increase in fiber wt. \%. It can be concluded that the tensile strength of NSL-Bamboo composite is more than NSL-PALF composite (almost double).

- Tensile modulus value initially increases with fiber wt. $\%$ and later declines with increase in fiber wt. $\%$. For Bamboo - NSL composite the maximum value of tensile modulus is observed at fiber content of 20 wt. \%, whereas for PALF- NSL composite the maximum value is observed at fiber content $10 \mathrm{wt} \%$. The tensile modulus value of Bamboo - NSL composite is almost double the value of PALF- NSL composite.

- Bending strength value increases with fiber wt. \% of up to certain maximum value and later decreases with further increase in fiber wt. \%. It is observed that the maximum bending strength is at fiber content of 20 wt. \%. At 20 wt. $\%$ Bamboo-NSL composite exhibits slightly superior strength when compared to PALF- NSL composite.

- Flexural modulus value also increases with fiber wt. \% upto certain limit and later decreases with further increase 
in fiber wt. \%. It is observed that flexural modulus value is maximum at fiber content of 20 wt. \%. The flexural modulus of Bamboo - NSL composite is almost three times the value of PALF- NSL composite.

- Impact strength value increases with fiber wt. \% up to certain limit and later declines with increase in fiber wt. $\%$. The maximum impact strength is noticed at $20 \mathrm{wt}$ \% of fiber. The impact strength of PALF- NSL composite is superior to Bamboo-NSL composite.

- Initially the strength of composite increases as fiber wt. \% increases and there is a proper bonding between fibers and matrix. Later as the fiber wt. \% increases strength of the composite decreases due to improper bonding between fibers and resin because of agglomeration of fibers.

- From the above study, it can be concluded that Bamboo fiber composite exhibits better properties in tensile and flexural applications whereas PALF composite exhibits better properties in impact loading applications.

\section{REFERENCES}

1. Singh, Harpreet, Jai Inder Preet Singh, Sehijpal Singh, Vikas Dhawan, and Sunil Kumar Tiwari. "A brief review of jute fibre and its composites." Materials Today: Proceedings 5, no. 14 (2018): 28427-28437.

2. Panyasart, Kloykamol, Nattawut Chaiyut, Taweechai Amornsakchai, and Onuma Santawitee. "Effect of surface treatment on the properties of pineapple leaf fibers reinforced polyamide 6 composites. "Energy procedia 56 (2014): 406-413.

3. Asim, M., M. Jawaid, K. Abdan, M. R. Ishak, and O. Y. Alothman. "Effect of hybridization on the mechanical properties of pineapple leaf fiber/kenaf phenolic hybrid composites." Journal of Renewable Materials 6, no. 1 (2018): 38-46.

4. Manikandan, V., S. Richard, M. Chithambara Thanu, and J. Selwin Rajadurai. "Effect of Fly Ash as Filler on Mechanical \& Frictional Properties of Jute Fiber Reinforced Composite." International Research Journal of Engineering and Technology 2, no. 07 (2015): 154-158.

5. Endah Susilowati, Didit Sumardiyanto. "Assessing Mechanical Properties of Pineapple Leaf Fiber (PLF) Reinforced Composites for Automotive Applications", International Journal of Composite Materials 2018, 8(3): 57-63.

6. Asim, M., Abdan, K., Jawaid, M., Nasir, M., Dashtizadeh, Z., Ishak, M.R. and Hoque, M.E., 2015. A review on pineapple leaves fibre and its composites. International Journal of Polymer Science, 2015.

7. Nurul Fazita, M. R., Krishnan Jayaraman, Debes Bhattacharyya, M. K. Mohamad Haafiz, Chaturbhuj K. Saurabh, M. Hazwan Hussin, and Abdul Khalil HPS. "Green composites made of bamboo fabric and poly (lactic) acid for packaging applicationsA review." Materials 9, no. 6 (2016): 435.

8. Arib, R. M. N., S. M. Sapuan, M. M. H. M. Ahmad, M. T. Paridah, and HMD Khairul Zaman. "Mechanical properties of pineapple leaf fibre reinforced polypropylene composites." Materials \& Design 27, no. 5 (2006): 391-396.

9. Selamat, Mohd Zulkefli, Mohd Daud Ahadlin, Mohd Yuhazri Yaakob, Putra Azma, and Dhar Malingam Sivakumar. "Mechanical properties of polypropylene composites reinforced with alkaline treated pineapple leaf fibre from Josapine cultivar." International Journal of Automotive and Mechanical Engineering (IJAME) 13, no. 1 (2016): 3157-3167.

10. Vignesh, V., S. Seetha, R. Shanmuga Priya, and BS Shiva Shankari. "Mechanical properties of hybrid pineapple/coconut sheath fibre reinforced polyester composites." International Journal of research in Mechanical, Mechatronics and Automobile Engineering (URMMAE) 2, no. 1 (2016): 16-22.

11. Jadhav, Panakaj, B. R. Sridhar, and Madeva Nagaral. "A comparative study on microstructure and mechanical properties of A356-B4C and A356-Graphite composites." International Journal of Mechanical and Production Engineering and 
Development 8.2 (2018): 273-282.

12. Dinesh, Tanniru, Andhra Pradesh Telaprolu, and S. Madhusudan. "Fabrication of Jute-Pine Apple leaf reinforced hybrid composites: Validation of mechanical properties through ANSYS." (2019).

13. Govindhasamy, K., and S. Arulmurugan. "Mechanical characterization of jute fibre nanocomposites." Int J Emerg Technol Comput Sci Electron 21 (2016): 521-524.

14. Das, Subrata Chandra, Debasree Paul, Mir Muhammad Fahad, Mithun Kumer Das, GM Shafiur Rahman, and Mubarak Ahmad Khan. "Effect of Fiber Loading on the Mechanical Properties of Jute Fiber Reinforced Polypropylene Composites." (2018). 